\title{
Parametric optimization of powder mixed Electro-discharge machining using Taguchi Technique
}

\author{
Shebin Thomas \\ PG Scholar, Dept. of Mechanical Engg, KCG College of Technology, Chennai \\ Dr. S. Ramesh \\ Professor, Dept. of Mechanical Engg, KCG College of Technology, Chennai \\ J. Jeykrishnan \\ Asst Professor, Dept. of Mechanical Engineering, Sri Sairam Engineering College, Chennai
}

\begin{abstract}
In the research work, a study has been made to optimize the input parameters of powder mixed electrical discharge machining (PMEDM). Taguchi technique has been employed to investigate the trials. Current, pulse on time, pulse off time have been chosen as input parameters to study the performances in terms of material removal rate and tool wear rate. Experiments are performed on a newly designed experimental setup developed in the laboratory. The results determine the most essential parameters to get maximum material removal rate and minimum tool wear rate. The confirmation experiments were done in order to justify the optimal process conditions.
\end{abstract}

Keywords: Material removal rate, tool wear rate, powder mixed EDM, Taguchi technique, Optimization

\section{INTRODUCTION}

Electrical discharge machining (EDM) is the widely used technique for processing the surfaces of dies. However, machining of these surfaces consumes more time because of the low material removal rate (MRR). Over the past few years, researchers have worked for improving the efficiency of the EDM process. An alternative method to improve efficiency was discovered by adding metal powder or alloy powder to the dielectric fluid. Proper input parameter values have been set for a particular combination of work piece-tool materials to optimize the EDM output performance; however, many researchers have carried out to determine optimal process parameters. The EDM process has many variables, which makes it difficult to attain an optimal set of input parameters. This has resulted in an increase in the cost of research work and studies. To ensure the economic efficiency of technical research in the EDM field, many different experimental design methods have been tested, including full factorial design, response surface methodology, and Taguchi methods. Some of the research methods followed in the field of PMEDM is described here. The effect of the electrical conductivity of the powder mixed into the dielectric fluid has been examined by many researchers. The chromium powder concentration ( 2 to 6 gram/litre), electrical discharge intensities and electrode size were the parameters that strongly influence the MRR and tool wear rate (TWR) [1]. Graphite powder (10 $\mu \mathrm{m}, 4$ gram/litre) mixed in the dielectric fluid increases and decreases the MRR and TWR by $68 \%$ and $28 \%$, respectively. [2]. The surface roughness $\left(\mathrm{R}_{\mathrm{a}}\right)$ and other surface properties of H13 steel were found to be affected by the electrode size in PMEDM using silicon powder [3,4]. An increase in electrode size increases the $\mathrm{R}_{\mathrm{a}}$ and alters the thickness of the white layer. The aluminum powder mixed into the dielectric fluid increases the MRR in EDM [5]. The optimal values of the electrical parameters of PMEDM using silicon powder were identified as developmental directions in EDM [6]. Boric acid $\left(\mathrm{H}_{3} \mathrm{BO}_{3}\right)$ powder had a milder effect on the $\mathrm{R}_{\mathrm{a}}$, MRR and TWR than graphite (Gr) powder [7]. Increasing the concentration of boric acid powder results in an increase in the MRR and microscopic surface hardness and reduces the TWR and $R_{a}$. Using aluminum powder $(300-400 \mu \mathrm{m})$ increases the MRR and decreases the TWR and $\mathrm{R}_{\mathrm{a}}$; this improves the productivity and quality of the machining process [8]. Concentration of the silicon powder and intensity of the electrical discharge are parameters that strongly influence the MRR [9]. When Gr powder is used, the TWR of thermally treated copper is lower than that of non-thermally treated copper [10]. The machining of 718 grade stainless steel using Al powder showed that opposite electrode polarity led to an increase in the MRR. Taguchi methods were used to optimize the processes, which contributed to improved quality and lower production costs [11]. The effect of current, pulse-on time, and pulse-off time on the TWR of copper electrodes during the machining of EN31 grade steel was assessed using Taguchi methods [12]. The results showed that adding powder reduced the TWR, whereas an increase in current 
and pulse-on time increased the TWR. Negative electrode polarity and Al powder mixed into the dielectric fluid reduced the $\mathrm{R}_{a}$ of an $\mathrm{H} 13$ steel work piece [13]. $\mathrm{R}_{\mathrm{a}}$ increased with increased current and duration of the pulses. Powder mixed in the dielectric fluid led to an increase in the MRR and led to a maximum MRR at a powder concentration of $6 \mathrm{~g} / 1$ [14]. Both MRR and $\mathrm{R}_{\mathrm{a}}$ were influenced by the concentration of powder and intensity of the electrical discharge [15]. The PMEDM process efficiency showed better results than the plain EDM process [16]. Three different powder materials were used in the dielectric media: Gr, silicon carbide (SiC) and aluminum oxide $\left(\mathrm{Al}_{2} \mathrm{O}_{3}\right)$. Gr powder increased the MRR and $\mathrm{SiC}$ powder reduced the TWR [17]. The use of $\mathrm{SiC}$ powder significantly improved the productivity of the EDM process during the machining of tungsten carbide (WC) [18]. The MRR with PMEDM was $90 \%$ higher than the EDM process. The maximum value of MRR was obtained by Taguchi methods at a powder concentration of $8 \mathrm{~g} / \mathrm{l}$. Studying the effect of the amount and concentration of $\mathrm{Al}$ powder on the MRR, TWR, and $\mathrm{R}_{\mathrm{a}}$ indicated that extreme values of both factors led to an increase in the MRR [19]. TWR and $R_{a}$ both reduced when metal powder or alloy powder was mixed with the dielectric fluid. PMEDM studies have shown that this is a very promising method to improve the productivity and quality of the work piece. The influence of titanium powder mixed with the dielectric fluid in EDM on the SR and micro-hardness (HV) of surface machining is shown in some studies [20-22]. However, the effect of using zirconium powder in PMEDM on the MRR and TWR has not been published yet. In order to assess comprehensively the influence of zirconium powder mixed in the dielectric fluid in fine machining by PMEDM, this study examined the optimization of the MRR and TWR during machining of D2 Die Steels using zirconium powder mixed in the dielectric fluid. The influence of the process parameters on the MRR and TWR was investigated using Taguchi methods.

\section{EXPERIMENTAL PROCEDURE}

From the literature survey, it has been observed that considerable work has been done on various aspects of electrical discharge machining of low carbon steels, carbides, few die steels but sufficient data is not available on powder mixed EDM D2 Die steel even though it is widely used in die and mould making industries. There is a need to investigate the machining of this material with copper electrode and using powder mixed EDM oil as dielectric fluid by varying different machining parameters like current, pulse on time and pulse off time. D2 Die stel steel (Dimensions: $62.5 \mathrm{~mm} \times 50 \mathrm{~mm} \times 10 \mathrm{~mm}$, and Composition: $\mathrm{C}=1.4-1.6 \%, \mathrm{Mn}=0.60 \%, \mathrm{Si}=0.60 \%$, $\mathrm{Cr}=11-13 \%, \mathrm{Ni}=0.3 \%, \mathrm{Mo}=0.7-1.2 \%, \mathrm{~V}=1.1 \%, \mathrm{Cu}=0.25 \%, \mathrm{P}=0.03 \%, \mathrm{~S}=0.03 \%, \mathrm{Fe}=$ remaining $\%)$ is selected as work material because of its high abrasion resistance, excellent wear resistance and high compressive strength. The electrode material selected for the present work is copper $(99.99 \% \mathrm{Cu})$ electrode and the powder selected is zirconium powder of 300 mesh size (46 microns). Experiments have been performed on Sparkonix S25/50 ZNC EDM with newly designed experimental setup consisting of mild steel tank placed in the work tank. Various machining conditions used during experimentation are listed in table 1. In this work, 9 experiments were conducted at the stipulated conditions and their levels were given in table 2 and the main objective of this paper is to maximize the material removal rate and also to minimize the tool wear rate.

Table 1: Machining conditions

\begin{tabular}{|l|c|}
\hline Tool & Copper \\
\hline Work piece & D2 Die Steel \\
\hline Polarity & Straight \\
\hline Time of trial & $\mathbf{1 0 ~ m i n s}$ \\
\hline Dielectric & EDM Oil \\
\hline Voltage & $\mathbf{6 0 ~ V}$ \\
\hline
\end{tabular}

Table 2: Parameters and levels
\begin{tabular}{|l|c|c|c|}
\hline Parameters & Level 1 & Level 2 & Level 3 \\
\hline Current $(\mathrm{A})$ & 5 & 6 & 7 \\
\hline Pulse on time $(\mu \mathrm{s})$ & 9 & 49 & 99 \\
\hline Pulse off time $(\mu \mathrm{s})$ & 2 & 6 & 9 \\
\hline
\end{tabular}

\section{MACHINING RESPONSES}

Material removal rate (MRR) and tool wear rate (TWR) has been selected as the output responses in this research work and the formula for calculating the MRR and TWR were shown in eqn (1) and eqn (2). MRR is defined as the total weight of the material removed or machined to the machining time.

$$
\operatorname{MRR}=[(\text { Initial }- \text { Final }) \text { weight } / \text { time }]
$$


Similarly, the tool wear rate is nothing but the amount of tool removed during machining and it has been calculated using

$$
\text { TWR }=[(\text { Initial }- \text { Final }) \text { weight } / \text { time }]
$$

\section{RESULTS AND DISCUSSIONS}

After experimentation, the analysis and discussion of results have to be carried out. In this section the effect of input parameters such as current, pulse on time and pulse off time on MRR and TWR were presented. The plots showing the effect of parameters on responses have drawn accounting the effect of all factors. Table 3 shows the input parameters and their responses.

\begin{tabular}{|c|c|c|c|c|c|}
\hline \multicolumn{7}{|c|}{ Table 3: Input parameters with their responses } \\
\hline Parameters & Current & Pulse on time & Pulse off time & $\begin{array}{c}\text { MRR } \\
(\mathrm{g} / \mathrm{min})\end{array}$ & $\begin{array}{c}\text { TWR } \\
(\mathrm{g} / \mathrm{min})\end{array}$ \\
\hline 1 & 5 & 9 & 2 & 0.0652 & 0.0301 \\
\hline 2 & 5 & 49 & 6 & 0.0965 & 0.0021 \\
\hline 3 & 5 & 99 & 9 & 0.1571 & 0.0036 \\
\hline 4 & 6 & 9 & 6 & 0.0682 & 0.0093 \\
\hline 5 & 6 & 49 & 9 & 0.0985 & 0.0028 \\
\hline 6 & 6 & 99 & 2 & 0.1678 & 0.0033 \\
\hline 7 & 7 & 9 & 9 & 0.0695 & 0.0055 \\
\hline 8 & 7 & 49 & 2 & 0.1011 & 0.0022 \\
\hline 9 & 7 & 99 & 6 & 0.1598 & 0.0027 \\
\hline
\end{tabular}

\section{EFFECT OF INPUT PARAMETERS ON MRR}

The signal to noise $(\mathrm{S} / \mathrm{N})$ ratio for MRR has been obtained using MINITAB 15 software and has been shown in fig 1 .

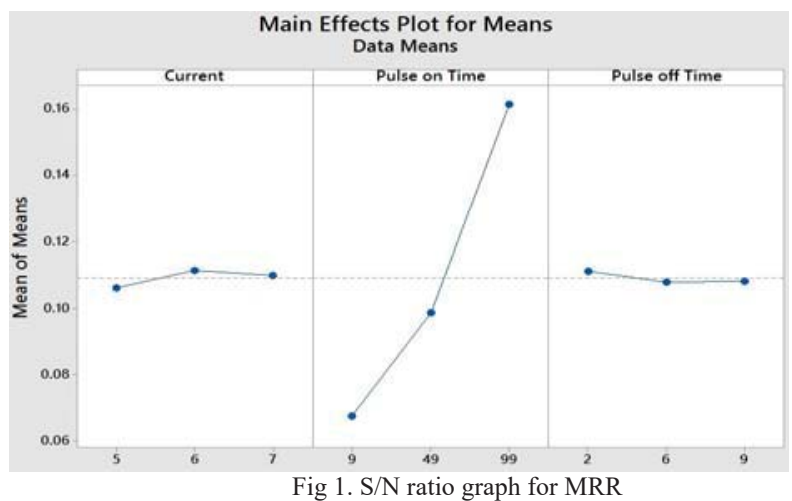

From fig 1, it is clear that the MRR increases up to certain point as the current increases, and then drops whereas there is a sharp increase and decrease of MRR in pulse on time and pulse off time, respectively. The optimal values are A2-B3-C1, i.e. current 6A, pulse on time and pulse off time are $99 \mu$ s and $2 \mu$ s, respectively. The response table for MRR are given in table 4, as this indicates the most significant parameter is current, followed by pulse on time and pulse off time. ANOVA has been carried out to indicate the significance of individual 
process parameters and this has been produced in table 5. It's been clear that, the current is the most significant parameter with $72.3 \%$, followed by pulse on time with $24.3 \%$ and the pulse off time with $2.7 \%$.

Table 4. Response table for MRR

\begin{tabular}{|c|c|c|c|}
\hline Level & Current (A) & Pulse on time $(\boldsymbol{\mu s})$ & Pulse off time $(\boldsymbol{\mu s})$ \\
\hline 1 & -23.40 & -20.03 & -19.71 \\
\hline 2 & -20.12 & -19.65 & -19.85 \\
\hline 3 & -15.84 & -19.66 & -19.79 \\
\hline Delta & 7.56 & 0.38 & 0.15 \\
\hline Rank & 1 & 2 & 3 \\
\hline
\end{tabular}

Table 5. Anova Table for MRR

\begin{tabular}{|c|c|c|c|c|c|}
\hline Parameters & Deg. Of freedom & S of Sq & Var & F values & P (\%) \\
\hline Current $(\mathrm{A})$ & 2 & 6.17 & 1.13 & 40.26 & 72.3 \\
\hline Pulse on time $(\mu \mathrm{s})$ & 2 & 2.07 & 0.167 & 5.96 & 24.3 \\
\hline Pulse off time $(\mu \mathrm{s})$ & 2 & 0.23 & 0.071 & 2.56 & 2.7 \\
\hline Error & 2 & 0.06 & 0.028 & -- & 0.7 \\
\hline Total & 8 & 8.533 & -- & -- & 100 \\
\hline
\end{tabular}

\section{EFFECT OF INPUT PARAMETERS ON TWR}

The $\mathrm{S} / \mathrm{N}$ ratio for TWR has been obtained and has been shown in fig 2., and it is clear that the TWR increases up to certain point as the current increases, and then drops whereas again there is a sharp increase and decrease of TWR in pulse on time and pulse off time, respectively. The optimal values are A1-B1-C3, i.e. current 5A, pulse on time and pulse off time are $9 \mu \mathrm{s}$ and $9 \mu \mathrm{s}$, respectively. The response table for TWR are given in table 6 , as this indicates the most significant parameter is current, followed by pulse on time and pulse off time. ANOVA has been carried out to indicate the significance of individual process parameters that affects the TWR and this has been produced in table 7. It's been clear that, the current is the most significant parameter with $65.44 \%$, followed by pulse on time with $19.32 \%$ and the pulse off time with $11.26 \%$.

Table 6. Response table for TWR

\begin{tabular}{|c|c|c|c|}
\hline Level & $\begin{array}{c}\text { Current } \\
(\mathbf{A})\end{array}$ & $\begin{array}{c}\text { Pulse on time } \\
(\boldsymbol{\mu s})\end{array}$ & $\begin{array}{c}\text { Pulse off time } \\
(\boldsymbol{\mu s})\end{array}$ \\
\hline 1 & 38.75 & 44.29 & 44.40 \\
\hline 2 & 52.59 & 47.11 & 48.52 \\
\hline 3 & 49.96 & 49.91 & 48.37 \\
\hline Delta & 13.84 & 5.62 & 4.12 \\
\hline Rank & 1 & 2 & 3 \\
\hline
\end{tabular}




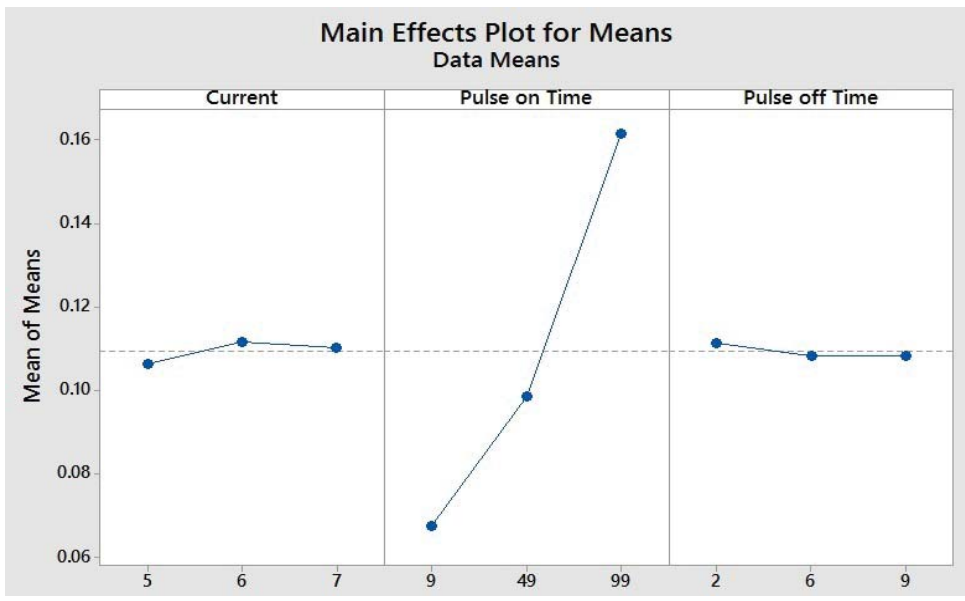

Fig 2. $\mathrm{S} / \mathrm{N}$ ratio graph for TWR

Table 7. Anova Table for TWR

\begin{tabular}{|c|c|c|c|c|c|}
\hline Parameters & Deg. Of freedom & S of Sq & Var & F values & P (\%) \\
\hline Current $(\mathrm{A})$ & 2 & 10.83 & 55.56 & 35.62 & 65.44 \\
\hline Pulse on time $(\mu \mathrm{s})$ & 2 & 3.20 & 20.67 & 13.25 & 19.32 \\
\hline Pulse off time $(\mu \mathrm{s})$ & 2 & 1.86 & 8.77 & 5.62 & 11.26 \\
\hline Error & 2 & 0.658 & 1.56 & -- & 3.98 \\
\hline Total & 8 & 16.55 & -- & -- & 100 \\
\hline
\end{tabular}

\section{CONCLUSION}

This article has presented an investigation on the optimization of machining parameters on the MRR and TWR in EDM. The significance of the parameters on MRR and TWR is determined by using ANOVA. Based on ANOVA, current with 6A have been found to be significant parameter for best MRR and the same current with $5 \mathrm{~A}$ plays a significant role in the tool wear rate. With the increasing in pulse on time, the MRR increases but it falls when the pulse off time increases. The similar case has been found with TWR also. The results were confirmed experimentally at $95 \%$ confidence interval. The future scope of this research work is to attempt with different dielectric materials with optimized process parameters.

\section{REFERENCES}

[1] Ojha K, Garg RK, Singh KK (1981) Experimental investigation and modeling of PMEDM process with chromium powder suspended dielectric. Int J Appl Sci Eng Technology

[2] Jeswani ML (1981) Effect of the addition of graphite powder to kerosene used as the dielectric fluid in electrical discharge machining. Wear 70:133-139

[3] Peças P, Henriques E (2003) Influence of silicon powder-mixed dielectric on conventional electrical discharge machining. Int J Mach Tools Manuf 43:1465-1471

[4] Peças P, Henriques E (2008) Electrical discharge machining using simple and powder-mixed dielectric: the effect of the electrode area in the surface roughness and topography. J Mater Process Technol 200:250-258

[5] Zhao WS, Meng QG, Wang ZL (2002) The application of research on powder mixed EDM in rough machining. J Mater Process Technol 129:30-33

[6] Kansal HK, Singh S, Kumar P (2005) Parametric optimization of powder mixed electrical discharge machining by response surface methodology. J Mater Process Technol 169:427-436

[7] Kansal HK, Singh S, Kumar P (2007) Technology and research developments in powder mixed electric discharge machining (PMEDM). J Mater Process Technol 184:32-41

[8] Özerkan B, Çoğun C (2005) Effect of mixed dielectric on machining performance in electric discharge machining. Gazi University Journal of Science 18

[9] Singh P, Kumar A, Beri N, Kumar V (2010) Influence of electrical parameters in powder mixed electric discharge machining (PMEDM) of hastelloy. Journal of Engineering Research and Studies 1:93-105

[10] Kansal HK, Singh S, Kumar P (2007) Effect of silicon powder mixed EDM on machining rate of AISI D2 die steel. J Manuf Process 9

[11] Kumar A, Maheshwari S, Sharma S, Beri N (2010) Effect of aluminium powder characteristics in additive electric discharge machining of nickel based super alloy Inconel 718. 2nd International Conference on Production and Industrial Engineering 
[12] Sanghani CRD, Acharya GD (2014) A review of research on improvement and optimization of performance measures for electrical discharge machining. Int Journal of Engineering Research and Applications 4:433-450

[13] Parkash V, Kumar D (2014) Effect of powder mixed dielectric medium on tool wear rate in EDM. International Journal of Scientific Research (IJSR) 2:107-109

[14] Singh G, Singh P, Tejpal G, Singh B (2012) Effect of machining parameters on surface roughness of H13 steel in EDM process using powder mixed fluid. International Journal of Advanced Engineering Research and Studies 2:148-150

[15] Rajendra M, Rao GKM (2014) Experimental evaluation of performance of electrical discharge machining of D3 die steel with A12O3 abrasive mixed dielectric material by using design of experiments. International Journal of Scientific Engineering and Technology 3: 599-606

[16] Kumar V, Rajpal M, Singh M (2014) Experimental study of surface parameters of EN31 on powder mixed EDM using Taguchi methodology. International Journal for Scientific Research \& Development 2:122-125

[17] Razak AM, Abdul-Rani AM, Nanimina AM (2015) Improving EDM efficiency with silicon carbide powder mixed dielectric fluid. International Journal of Materials, Mechanics and Manufacturing 3: 40-43

[18] Rathi MG, Mane DV (2014) Study on effect of powder mixed dielectric in EDM of Inconel 718. International Journal of Scientific and Research Publications 4:1-7

[19] Kaldhone SY, Kavade MV, Rawat U (2014) Effect of powder mixed dielectric on performance measures of EDM for tungsten carbide. International Journal of Innovative Research in Advanced Engineering (IJIRAE) 1:106-111

[20] Furutani K, Saneto A, Takezawa H, Mohri N, Miyake H (2001) Accretion of titanium carbide by electrical discharge machining with powder suspended in working fluid. Precis Eng 25:138-144

[21] Furutani K, Sato H, Suzuki M (2009) Influence of electrical conditions on performance of electrical discharge machining with powder suspended in working oil for titanium carbide deposition process. Int J Adv Manuf Technol

[22] Janmanee P, Muttamara A (2012) Surface modification of tungsten carbide by electrical discharge coating (EDC) using a titanium powder suspension. Applied Surface Science 258: 7255-7265 